\title{
ONTO-THESAURI: AN EFFICIENT ONTOLOGY!
}

\author{
F. Vandamme ${ }^{1} \&^{2}$, L. Wang ${ }^{2}$, M. Vandamme ${ }^{3}$ and P. Kaczmarski ${ }^{3}$ \\ LAAE, Ghent University, Blandijnberg 2, 9000 Gent, Belgium \\ 2BIKIT vzw, J. Plateaustraat 22, 9000 Gent, Belgium \\ 3 VARTEC NV, Holstraat 19, 9000 Gent \\ Fernand.Vandamme@ugent.be, www.Ugent.be \\ Lin.Wang@bikit.org,www.bikit.org \\ Mike.Vandamme@vartec.behttp://www.vartec.bel \\ Peter.Kaczmarski@vartec.be
}

Abstract: There is an eternal problem for enterprise content management: "Everyday living is too fast, too busy, too complicated. More than at any time in history, it's important to have good information on just about every aspect of life. And, An onto-thesaurus based document and content management platform is very successful. It provides an improvement of recall and precision of information retrieval by ISO mono-lingual or multilingual thesauri indexing, homonymy resolution and onto-thesaurus.

Key words: onto-thesauri, knowledge retrieval, knowledge management, ontology

\section{INTRODUCTION: HOW TO HAVE EFFICIENT KNOWLEDGE RETRIEVAL, WITH PRECISION:}

There is an eternal problem for enterprise content management: "Everyday living is too fast, too busy, too complicated. More than at any time in history, it's important to have good information on just about every aspect of life. And, there is more information available than ever before. Too much in fact. There is simply no time for people to gather and absorb the information they need." Britton Hadden - 1929. The goal for the solution is improving retrieval recall and precision. In this paper we will introduce an onto-thesaurus approach. 


\section{A HIGH SUCCESSFUL SOLUTION: AN ONTO- THESAURUS ENHANCED WITH MULTILINGUAL QUALITY AND HOMONYMS DETECTION}

An onto-thesaurus based document and content management platform is very successful. It provides an improvement of recall and precision of information retrieval by ISO mono-lingual or multilingual thesauri indexing, homonymy resolution and onto-thesaurus.

It includes following modules:

\section{1 modules for (onto)-Thesaurus life cycle (see fig 1):}

IKEM.ThesCreator ${ }^{\mathrm{TM}}$

IKEM.ThesEditor ${ }^{\mathrm{TM}}$

IKEM.ThesAnnot ${ }^{\mathrm{TM}}$

\subsubsection{IKEM.ThesCreator ${ }^{\mathrm{TM}}$}

Users can develop a (onto)-Thesaurus using document corpus/content by IKEM.ThesCreatorTM. It provides a simultaneous view of (onto-)thesaurus relations and document content, context of current thesaurus terms and context of full index terms. User can simultaneous updating of the (onto-) thesaurus

\subsubsection{IKEM.ThesEditor ${ }^{\mathrm{TM}}$}

The powerful thesaurus editor system supports ISO relations (mono \& multi-lingual), homonym resolution, enhancement of ISO standard Relation, consistence checking, circular relations checking. It also supports intuitive graphical thesaurus development and support for multi-lingual \& multidomain

\subsubsection{IKEM.ThesAnnot ${ }^{\mathrm{TM}}$}

The IKEM.ThesAnnotTM can thread annotations of the thesaurus terms managed via a web service which support multiple user and discussion for maintenance of thesaurus. 


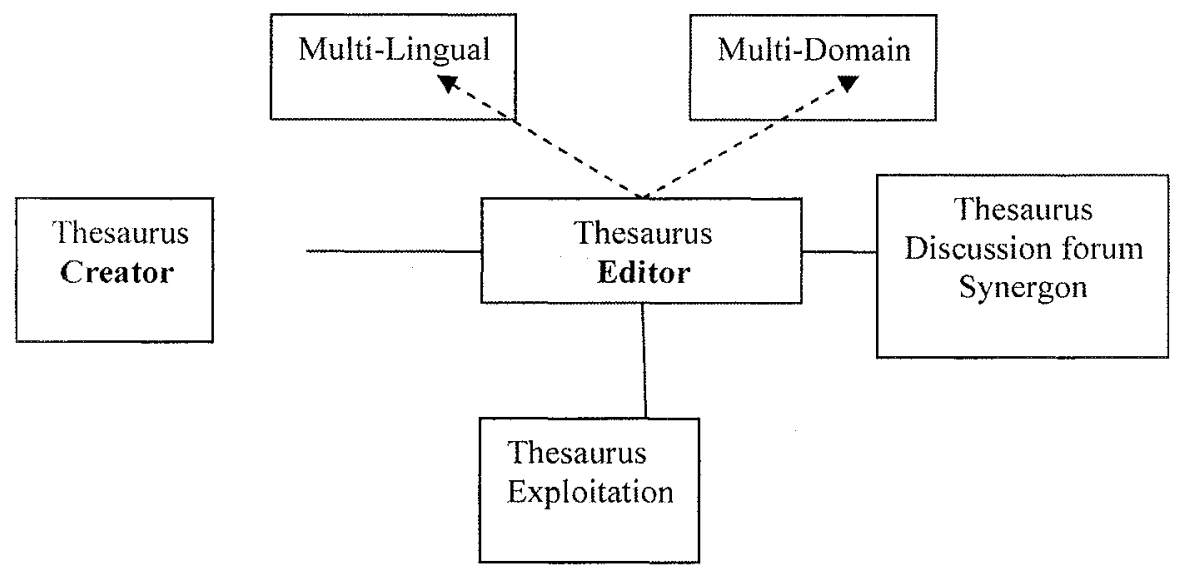

Fig 1. (onto)-Thesaurus life cycle

\section{2 modules for (onto)-Thesaurus exploitation (see fig.2)}

IKEM.DocSearch $^{\mathrm{TM}}$ and IKEM.Query-Expansion ${ }^{\mathrm{TM}}$ IKEM.3D-Navigation $^{\mathrm{TM}}$

IKEM.Onto-thesaurus $^{\mathrm{TM}}$ and 3D-Search ${ }^{\mathrm{TM}}$

\section{(onto)-Thesaurus Exploitation}

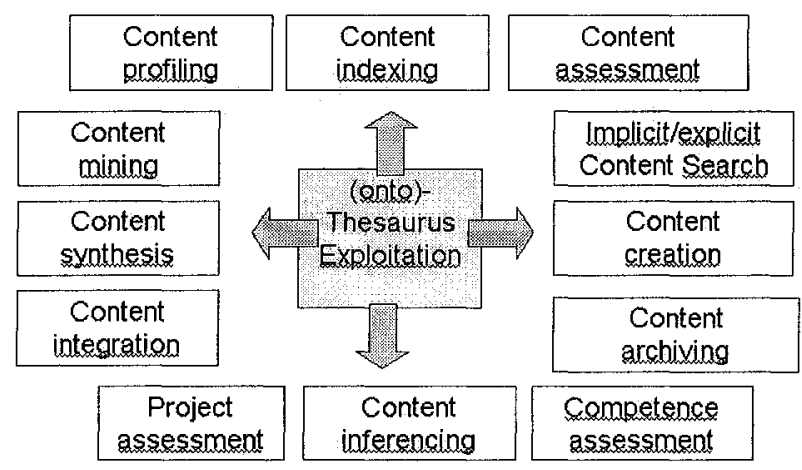

Fig.2 (onto)-thesaurus exploitation 


\section{IKEM - Interactive Knowledge Management}

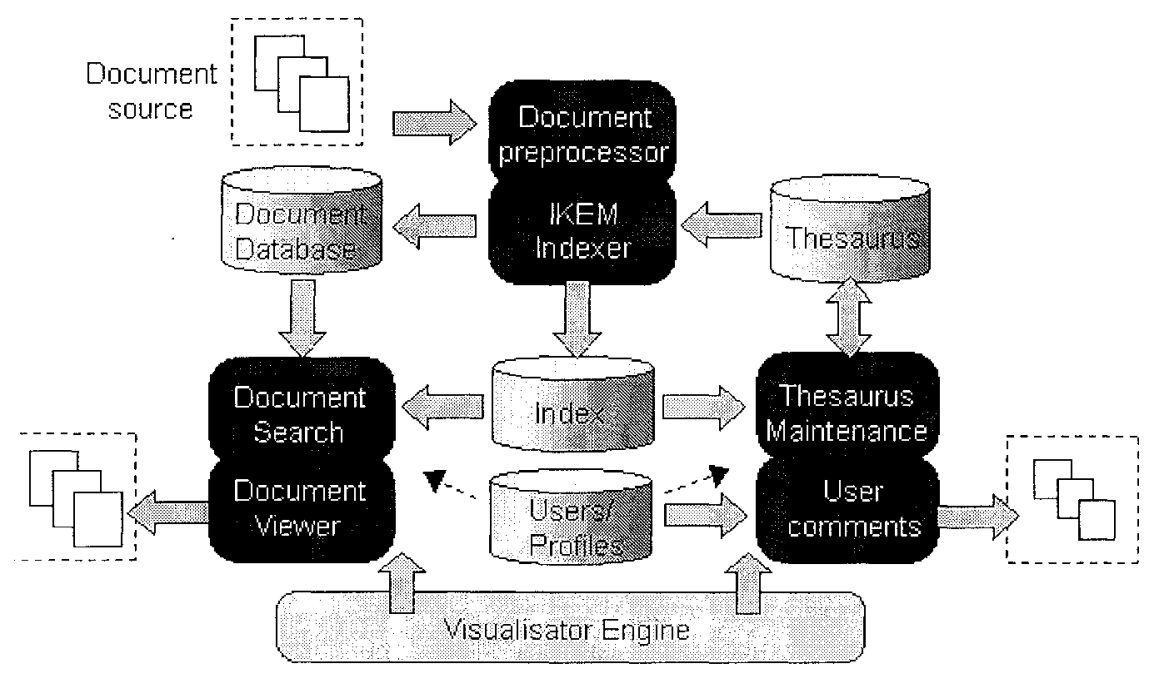

Fig. 3 IKEM platform for document and content management

\subsubsection{IKEM.DocSearch ${ }^{\mathrm{TM}}$ and IKEM.Query-Expansion ${ }^{\mathrm{TM}}$}

IKEM through web services supports user query in different languages, query expansion based on thesaurus and onto-thesaurus.

\subsubsection{IKEM.3D-Navigation ${ }^{\mathrm{TM}}$}

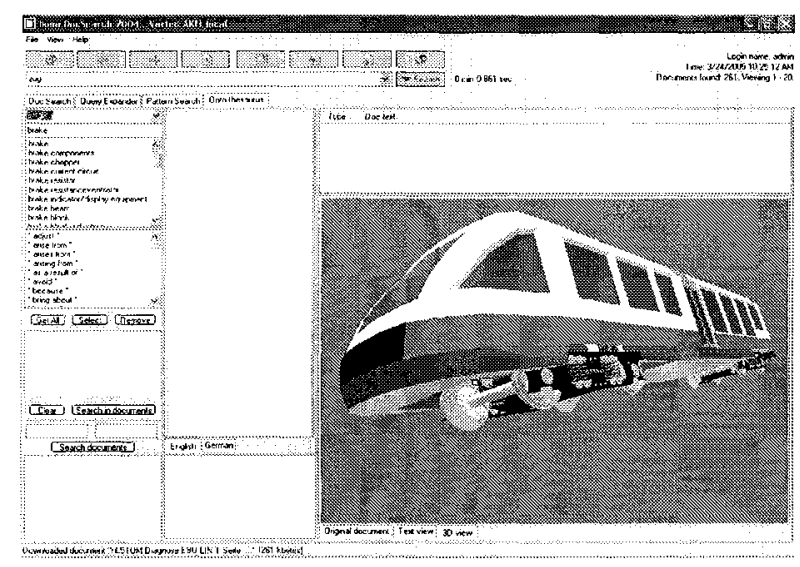

Fig 4 IKEM search via 3D space navigation 


\subsubsection{IKEM.Onto-thesaurus ${ }^{\mathrm{TM}}$ and 3D-Search ${ }^{\mathrm{TM}}$}

IKEM offers users search by query extension and pattern search.

\subsubsection{Application of thesaurus and onto-thesaurus for assessment}

Assessment through project views:

a). Task view

-dynamic overview of tasks as a function of time

-can be linked with project- and task specification

b). Coordination view

-early warnings regarding possible delays in project realisation

c). Cooperation view

-using actor profiles to analyze the cooperation patterns

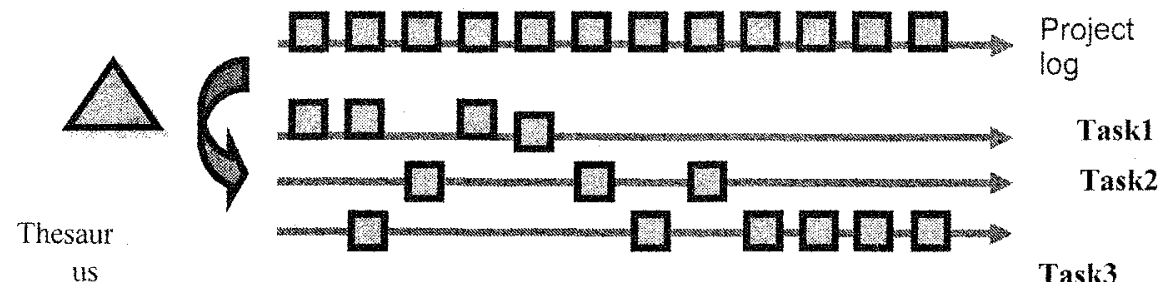

us

2. Coordination view

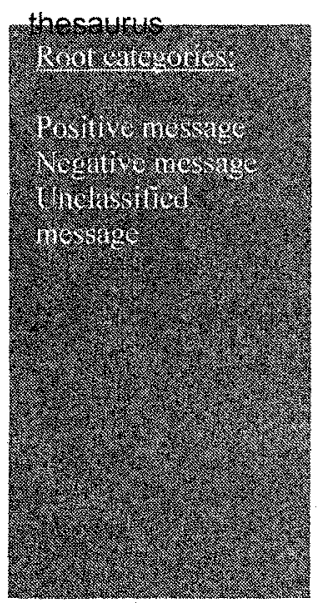

3. Actor profiles

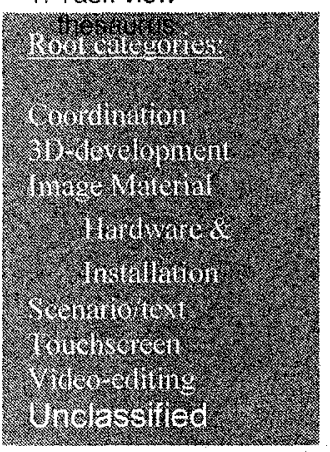

Fig .5 Assessment through project views

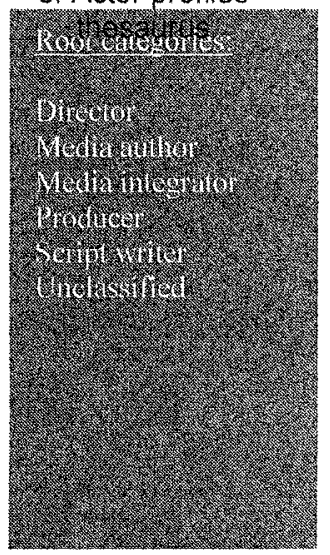




\section{CONCLUSIONS}

Thesauri \& Onto-Thesauri based document and content management can enhanced retrieval recall \& precision and Interactive Knowledge

Management. Onto-thesauri approach have the benefit that they can be build semi-automatically and can be used for automatic indexing and search. They have the main benefits as ontology, but their performance is much higher. (see fig. 6)

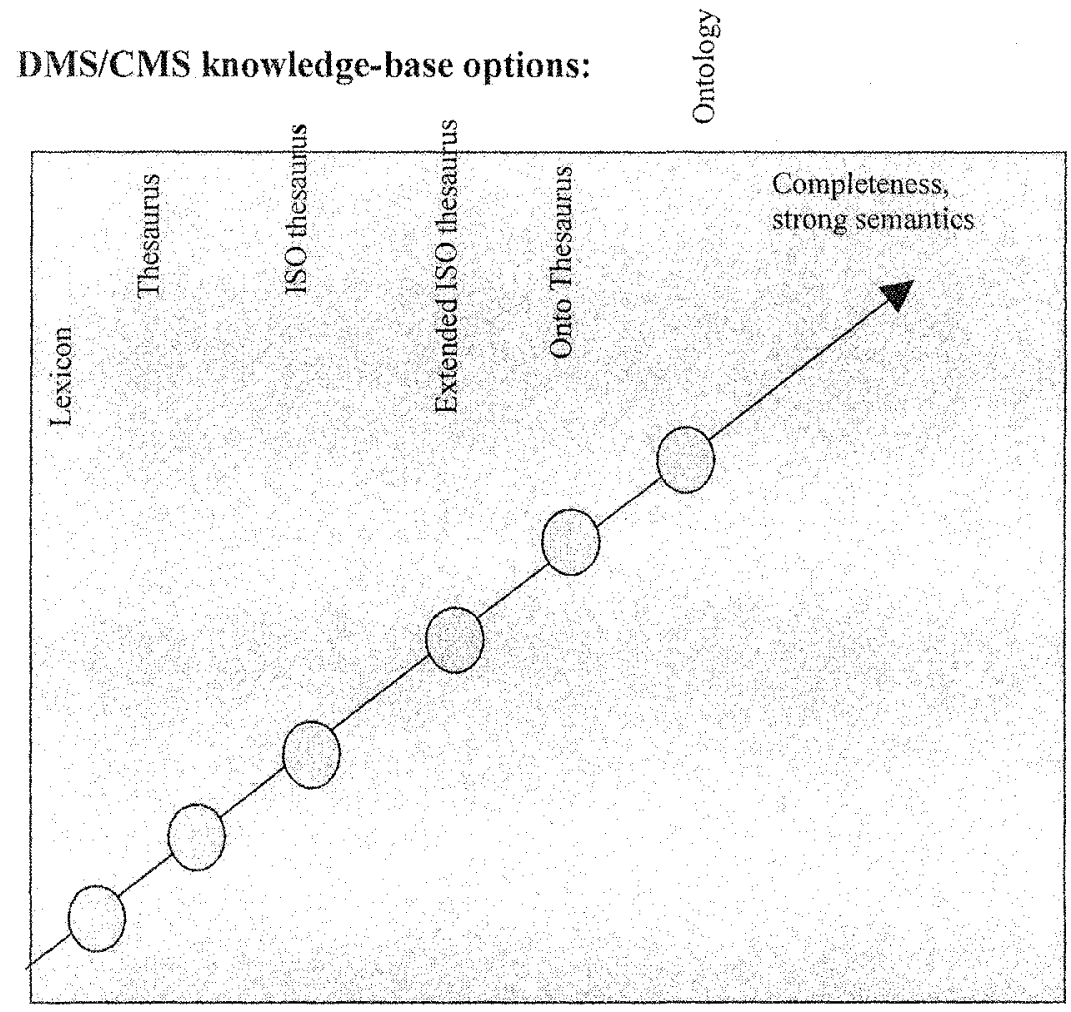




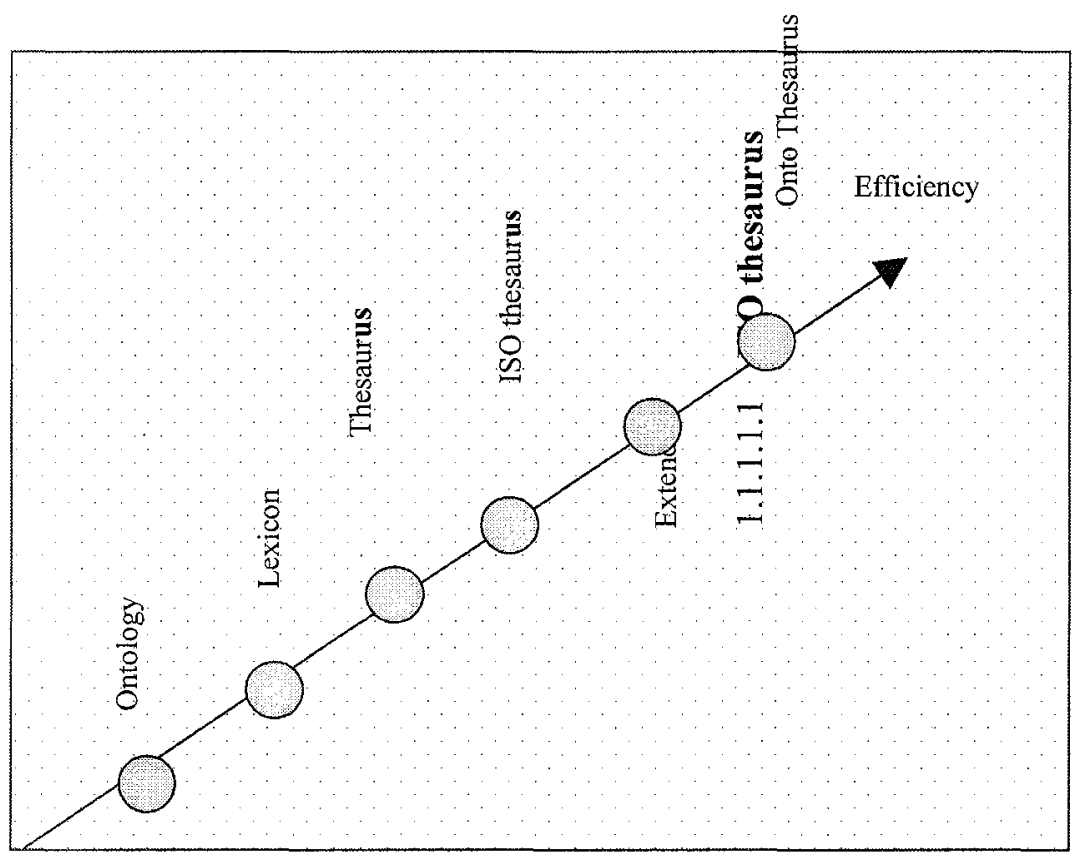

Fig. 6 DMS/CMS knowledge-base options

\section{REFDERENCES}

[1] Abuzir, Y., 2002, E-mail messages classification and user profiling by the use of semantic thesauri, Capita Selecta uit de Toegepaste Epistemologie, deel IX, Communication \& Cognition, Gent

[2] Vandamme, F, 2001, Learning and Education, CC-AI, Vol. $18 \mathrm{n}^{\circ} 1 / 2$, Communication \& Cognition, Gent

[3]Vandamme, F., Simmons, S., 2001, Advanced Content Management (ACM) for Project Process Assessment and Control. A Knowledge Management Approach., CC-AI, Vol. 18 $n^{\circ} 3 / 4$, Communication \& Cognition, Gent

[4] Vandamme F., 2002, Knowledge Management and its vital components, Capita Selecta uit de Toegepaste Epistemologie, deel IX, Communication \& Cognition, Gent

[5] Lin, W., Van Vosselen, N., Vandamme, F., 2004, Sustainability based project life-cycle management, Caleidoscoop of Knowledge Management, Communicatie \& Cognitie, Gent.

[6] Vandamme, F., 2004, Gandhi and Knowledge management, introduction, Communication \& Cognition, Vol. 37, nr. 1-2, pp. 3-4, Communication \& Cognition, Gent 